\title{
AUGMENTATION OF HEAT TRANSFER IN CORRUGATED TUBE USING FOUR-START SPIRAL WALL
}

\author{
Dr. Ghassan Fadhil SMAISIM \\ Mechanical Engineering Department, Kufa University, Iraq \\ E-mail:Ghassan.Smaisim@Uokufa.Edu.la
}

Received on 7August 2017 Accepted on 30 October 2017 Published on 15 January 2018

DOI: 10.30772/qjes.v10i4.493

\begin{abstract}
This article dealt with an important heat transfer field, which is passive heat transfer technique represented by corrugated tube. The study conducted numerically by ANSYS Fluent 14. The motivation behind the current study was to clarify the characteristics and merits of such tube geometry in terms of heat transfer and pressure drop. The obtained results reported under constant heat flux, temperature-dependent thermo-physical properties and Reynolds number range of 300-1500. Results show good heat transfer enhancement of 6.15-33.24\% in spite of an increase in friction factor of 1.80 2.93 times the smooth values. The corrugated tube with $\varphi=4.76 \times 10^{-2}$ has the top thermal 1.16-1.25 for all Reynolds number. The most important finding is that the gained heat transfer is much more than the increase in pressure loss until a certain threshold of Reynolds number about 900, later, the pressure loss increase and dominates over the heat gained. The effect of Prandtl number on the heat transfer for three types of fluids produced too. A criterion correlation equation of Nusselt number developed to describe the cases of four starts spirally corrugated tubes by deviation $\pm 3 \%$ compared with the simulation results.
\end{abstract}

Keywords: Corrugated Tubes; Four-Starts; Severity Index; Heat Transfer Enhancement; Friction Factor.

\section{INTRODUCTION}

Different types of the heat exchangers have been used in the electrical, chemical, automotive and industrial applications. One of the important types in a co-axial heat exchanger is the spirally corrugated tube, which can improve the overall heat transfer performance of the heat exchangers [1]. Corrugated tubes have been developed from single start to multiple starts. Corrugation augments the heat transfer due to the mix of fluid, which produced during the flow separation and then re-attaches stages [2].

It is imperative to find out a way for sharing resources and saving energy due to horrible energy exhausting. Axiomatically, energy resources are running short with, and the globe on the verge of imminent lack [1]. Heat transfer field holds the promises; it is the most important field that could be helpful in such issue. It can reduce the wasted energy significantly in the case of employing an effective and well functional technique in many applications, such as electronic device cooling, heat exchangers, and nuclear reactor cooling [3-7]. In general, the desired magnification of gained heat could be achieved by primarily two techniques. First one; produces a good outcome, but it needs external power and it is called "active technique"[8]. The second one; does not need any external power and it could be achieved by adding something to the fluid or modify the surface, this method is called "passive technique" [9]. There is another method which called "compound technique " which involves the two previous types (active and passive) like using an electrostatic field or vibrated flow which is active types in addition to use the nanofluid or vortex 


\section{AL-QADISIYAH JOURNAL FOR ENGINEERING SCIENCES}

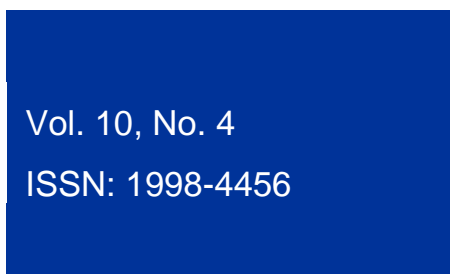

generators which are passive types [8,9]. Therefore, the active technique is not desirable, while the passive is suitable for many applications. In the last few years, passive heat transfer enhancement became very interested due to economical (saving energy) and environmental (weather mitigation) reasons [10]. Hence, many researchers investigate the passive heat transfer enhancement. One of the gurus in this field is Saha $[11,12]$, who paid great effort and conducted many studies especially laminar flow in rippled tubes. The studies were conducted at different boundary condition with various corrugation styles. The reported results showed a remarkable magnification in heat transfer with an increase in pressure drop for the flow in a tube with specific corrugation style. Kareem et. al. [2] introduces an extensive survey review article for the flow in corrugated tubes. Most of the whole studies regarding corrugation were taken into account. The master key of the corrugated tube is the corrugation style and profile as the mentioned review article stated. Moreover, the harmony of the flow and the enhancement of heat transfer directly proportion to the corrugation style and characteristics. In another study, the using innovative corrugation style can maximize the heat transfer and induce better flow pattern with pressure drop reduction as Kareem et. al. [13] stated. Chen et al. [14] carried out the fluid flow and heat characteristics of the four-start rippled pipe. They studied the influence of the corrugation angles, Reynolds number and pressure drop along the longitudinal direction. They concluded that as the angle ratio increases, the friction loss increases. Zimparov [15] investigated experimentally the fluid flow and heat transfer characteristics of a three-start rippled tube and studied the effect of variable relative pitches for twisted tape inserts in the tube. The results proved that the friction coefficients for whirl flow enlarged at the relative pitch H/Di reduced. Ahn [16] investigated experimentally the effect of four-start spirally corrugated tube on the heat transfer performance. The results illustrated that there is a good enhancement of heat transfer than the use of the smooth tube .Liu et al. [17] presented an experiment and numerical analysis of the heat transfer and hydrodynamic performance in a spirally corrugated cooler and studied the influence the depth of the corrugation with pitch ratio on the heat transfer characteristics, the results showed that corrugated tube augments the heat transfer efficiency. Then Liu et al. [18] investigated numerical model on the heat transfer of rippled tubes with many numbers of start spirally tubes (one start to four-starts). Results showed that the Nusselt number for four starts is higher than the one, two or three starts. Promthaisong et al. [19] carried out numerical simulation on heat transfer characteristics of forced convection in turbulent flow regime with the influence of Reynolds number and pitch ratio on the overall heat performance, they concluded that spirally tubes generate vortex to mix the flow during the tube that helps to enhance the heat transfer.

Accordingly, the current article deals with an innovative corrugated tube to enhance heat transfer in the laminar flow region using four spirally corrugated tube by study the effect of the five values of corrugation height $\mathrm{e}$, nominal diameter $\mathrm{D}_{\mathrm{n}}$, severity index $\varphi$, fluid properties and Reynolds number on the heat and pressure drop characteristics. In order to mimic the real case of the problem, the thermo-physical parameters of the working fluid were taking as a temperature-dependent under constant heat flux condition.

\section{MATHEMATIC MODEL}

First of all, one smooth and five corrugated tubes were created by utilizing SolidWorks software package. The tubes material was selected to be steel of $2 \mathrm{~mm}$ thickness and $2 \mathrm{~m}$ length. The bore diameter $D_{b}$ of all tubes remain constant at $10 \mathrm{~mm}$, on the other hand, the envelope diameter $D_{e}$ is varying from 12 to 14 $\mathrm{mm}$ with increment step of $0.5 \mathrm{~mm}$. The primary parameters that usually used to describe the rippled tube are the corrugation height $e$, corrugation pitch $p$, nominal diameter $D_{n}$ and the severity index $\varphi$ as shown in Figure 1 . 


\section{AL-QADISIYAH JOURNAL FOR ENGINEERING SCIENCES}

Vol. 10 , No. 4

ISSN: $1998-4456$

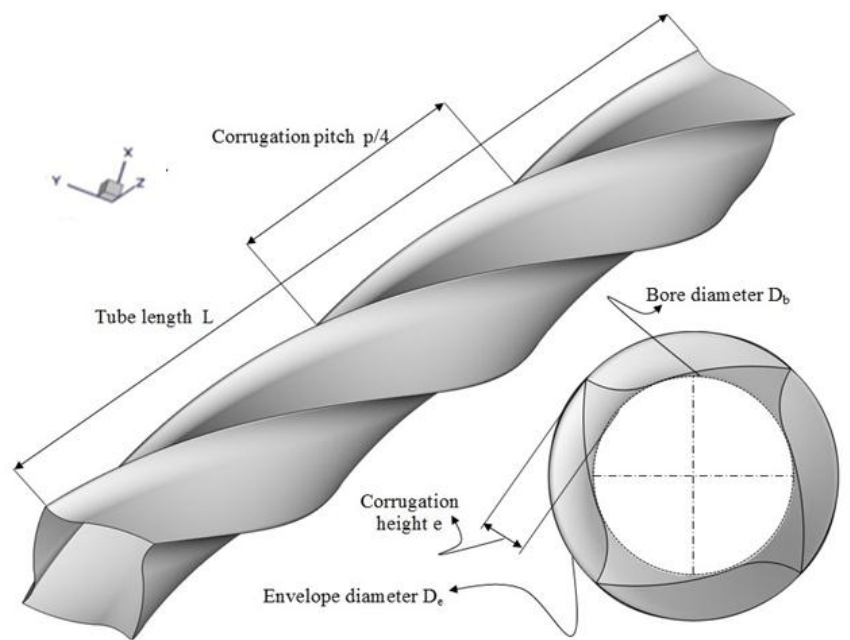

Figure 1: Corrugated Tube Geometry

Instead of discussing the effect of both corrugation height e and corrugation pitch $p$ individually, the expression of "severity index $\varphi$ " proposed which include the effect of both corrugation height and pitch. The severity index simply indicates how corrugation is severe and calculates from the following equation [2]:

$\varphi=\mathrm{e}^{2} /\left(p D_{n}\right)$

Where, $D_{n}$ nominal often used in corrugation to denote to diameter" due tube nominal be calculated following

$D_{n}=$

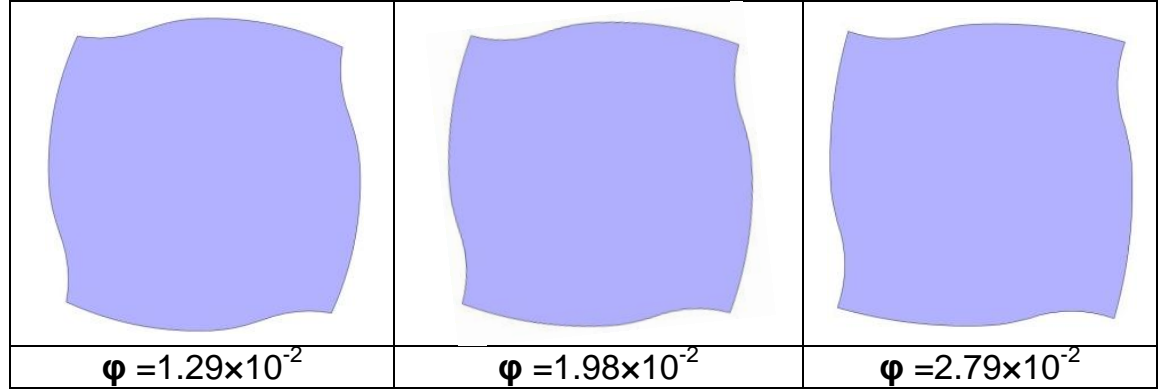

represents the diameter and it the tubes in order the "hydraulic to irregular geometry. The diameter could from the equation [10]:

$\left(D_{b}+D_{e}\right) / 2$

(2)

The tubes characteristic and dimensions that employed in the current simulations described in the Table 1 and the corresponding cross sections for the cases appear clearly in Figure 2.

TABLE 1: TUBES CHARACTERISTICS

\begin{tabular}{|c|c|c|c|c|c|c|}
\hline No. & $\mathbf{D}_{\mathbf{b}}$ & $\mathbf{D}_{\mathbf{e}}$ & $\mathbf{D}_{\mathbf{n}}$ & $\mathbf{e}$ & $\mathbf{P}$ & $\boldsymbol{\varphi}$ \\
\hline 1 & - & - & 10.00 & - & - & Smooth Tube \\
\hline 2 & 10 & 12.0 & 11.00 & 2.0 & 28 & $1.29 \times 10^{-2}$ \\
\hline 3 & 10 & 12.5 & 11.25 & 2.5 & 28 & $1.98 \times 10^{-2}$ \\
\hline 4 & 10 & 13.0 & 11.50 & 3.0 & 28 & $2.79 \times 10^{-2}$ \\
\hline 5 & 10 & 13.5 & 11.75 & 3.5 & 28 & $3.72 \times 10^{-2}$ \\
\hline 6 & 10 & 14.0 & 12.00 & 4.0 & 28 & $4.76 \times 10^{-2}$ \\
\hline
\end{tabular}




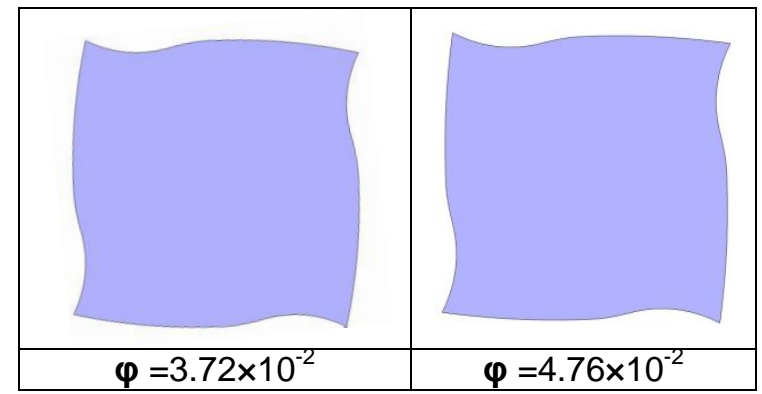

Figure 2: Case Studies of the Corrugated Tubes

\subsection{GOVERNING EQUATIONS}

The discretization of the governing equations should be made prior to simulation. For the flow of fluid in the tube, the following three equations are the main governing equations [8].

-Continuity Equation:

$$
\frac{\partial \mathrm{u}_{\mathrm{r}}}{\partial \mathrm{r}}+\frac{\mathrm{u}_{\mathrm{r}}}{\mathrm{r}}+\frac{1}{\mathrm{r}} \frac{\partial \mathrm{u}_{\theta}}{\partial \theta}+\frac{\partial \mathrm{u}_{\mathrm{z}}}{\partial \mathrm{z}}=0
$$

-Momentum Equation in z-direction (axial direction):

$$
\rho\left(\mathrm{u}_{\mathrm{r}} \frac{\partial \mathrm{u}_{\mathrm{z}}}{\partial \mathrm{r}}+\frac{\mathrm{u}_{\theta}}{\mathrm{r}} \frac{\partial \mathrm{u}_{\mathrm{z}}}{\partial \theta}+\mathrm{u}_{\mathrm{z}} \frac{\partial \mathrm{u}_{\theta}}{\partial \mathrm{x}}\right)=-\frac{\partial \mathrm{P}}{\partial \theta}+\mu\left(\frac{\partial^{2} \mathrm{u}_{\mathrm{z}}}{\partial \mathrm{r}^{2}}+\frac{1}{\mathrm{r}} \frac{\partial \mathrm{u}_{\mathrm{z}}}{\partial \mathrm{r}}+\frac{1}{\mathrm{r}^{2}} \frac{\partial^{2} \mathrm{u}_{\mathrm{z}}}{\partial \theta^{2}}+\frac{\partial^{2} \mathrm{u}_{\mathrm{z}}}{\partial \mathrm{z}^{2}}\right)
$$

-Energy Equation:

$$
\rho c_{p}\left(u_{r} \frac{\partial T}{\partial r}+\frac{u_{\theta}}{r} \frac{\partial T}{\partial \theta}+u_{z} \frac{\partial T}{\partial z}\right)=k\left[\frac{1}{r} \frac{\partial}{\partial r}\left(r \frac{\partial T}{\partial r}\right)+\frac{1}{r^{2}} \frac{\partial^{2} T}{\partial \theta^{2}}+\frac{\partial^{2} \mathrm{~T}}{\partial \mathrm{z}^{2}}\right]
$$

The other important heat transfer parameter can be compute by using analytical equation, such as local heat transfer coefficient (h), which can be computed as below:-

$$
\mathrm{h}(\mathrm{z})=\frac{\mathrm{q}_{\mathrm{s}}^{\prime \prime}(\mathrm{z})}{\left[\mathrm{T}_{\mathrm{w}}(\mathrm{z})-\mathrm{T}_{\mathrm{b}}(\mathrm{z})\right]}
$$

where, both $T_{w}(z)$ and $T_{b}(z)$ represent local wall and bulk temperatures respectively. While $q^{\prime \prime}{ }_{s}(z)$ is the locally applied heat flux, which can be determined by:-

$$
\begin{aligned}
& \mathrm{q}_{\mathrm{s}}^{\prime \prime}=\mathrm{Q}_{\text {Total }} / \mathrm{A}_{\mathrm{z}} \\
& \mathrm{A}_{\mathrm{z}}=\frac{\pi}{4} \mathrm{D}_{\mathrm{n}}^{2} \mathrm{z}
\end{aligned}
$$
equations:-

On the other hand, both of local and average Nusselt number determined from the following

$$
\begin{aligned}
& \mathrm{Nu}(\mathrm{z})=\frac{\mathrm{h}(\mathrm{z}) \mathrm{D}_{\mathrm{n}}}{\mathrm{k}(\mathrm{z})} \\
& \mathrm{Nu}=\frac{\mathrm{h}(\operatorname{avg}) \mathrm{D}_{\mathrm{n}}}{\mathrm{k}(\operatorname{avg})}
\end{aligned}
$$

Eventually, Reynolds number was determined from the following expression

$$
\operatorname{Re}=\frac{\rho \mathrm{u} \mathrm{D}_{\mathrm{n}}}{\mu}
$$

\subsection{NUMERICAL PROCEDURE AND BOUNDARY CONDITIONS}

ANSYS MESHING ICEM CFD 14 is the tool that employed for this purpose. Mesh process acting as an essential character in accuracy and reliability of the results. Tetrahedral elements of constant stress element owning four nodes were applied. For each node, the elements were represented in 3-Dim space 


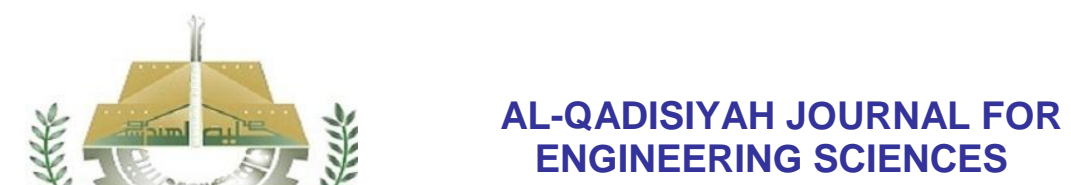
ENGINEERING SCIENCES
Vol. 10, No. 4

ISSN: $1998-4456$

possessing three degrees of freedom in $\mathrm{X}, \mathrm{Y}$ and $\mathrm{Z}$, directions with take care about the meshing qualities like mesh skewness, aspect ratios and mesh smooth that collected to be $0.75 \%, 1 \%$ and $20 \%$ respectively.

For consistency in the discretization scheme, the density of the grid plays an important parameter to get the right solution [20]. It is known that any increases in the density about the spatial grids will minimize the errors. Element number has an important parameter to get mesh dependence results as shown in Figure 3. In the current study, the grid density limits were 2763566-3094583 tetrahedral cells.

Grid Convergence Index $(\mathrm{GCl})$ was performed to verify the meshing quality [21]. Mesh spaces were tested for each case $0.1,0.2,0.3,0.4$ and $0.5 \mathrm{~mm}$ respectively, where the GCl's were $0.107,0.131,0.169$ and $0.205 \mathrm{~mm}$ respectively. Therefore, the mesh spacing of $0.1 \mathrm{~mm}$ was selected for the whole cases as shown in Figure 4. Moreover, the reduction in mesh spacing gives more stability and accurate outcome values, where the bulk fluid temperature becomes reasonable and has precise value, as the mesh space gets finer as shown in both Figures 3 and 4.

A commercial code of ANSYS FLUENT 14.0 [22] used to construct the fluid flow model of smooth and corrugated pipes. Semi-Implicit Method for Pressure Linked Equations (SIMPLE) algorithm produced to solve the Navier Stokes equations by coupling the pressure and velocity. In discrete arrangement, second order upwind chosen for computing momentum and energy while standard format chosen for pressure. Convergence conditions absolute value of energy residual is setting less than $1 \times 10^{-9}$, beside the value of other quality residuals are less than $1 \times 10^{-6}$. For all cases, the simulations conducted the stainless steel pipe under constant heat flux of $10 \mathrm{KW} / \mathrm{m}^{2}$, with steady state and temperature-dependent thermo-physical properties. The working fluid is Newtonian fluid as pure water enters at temperature $300 \mathrm{~K}$ with Reynolds number range was 300-1500.

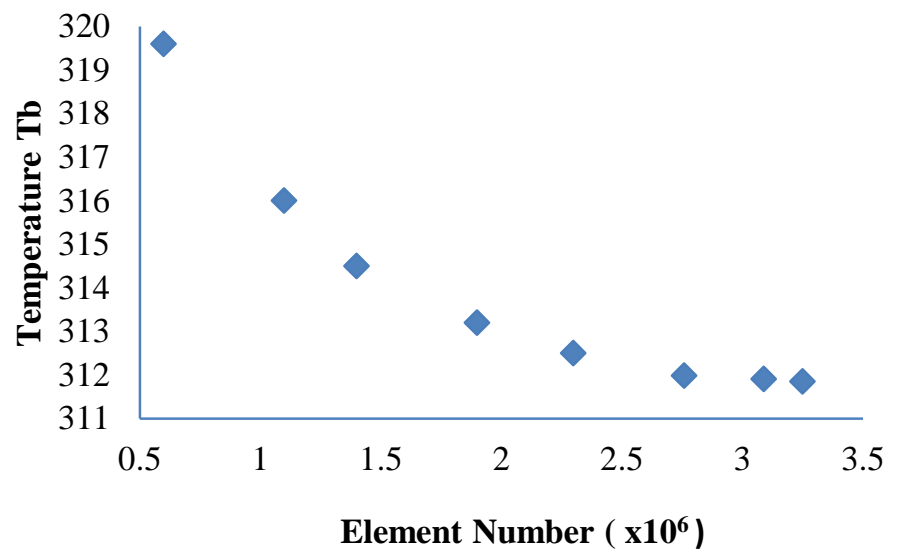

Figure 3: Element Number vice Bulk Temperature 


\section{AL-QADISIYAH JOURNAL FOR ENGINEERING SCIENCES}

Vol. 10 , No. 4

ISSN: $1998-4456$

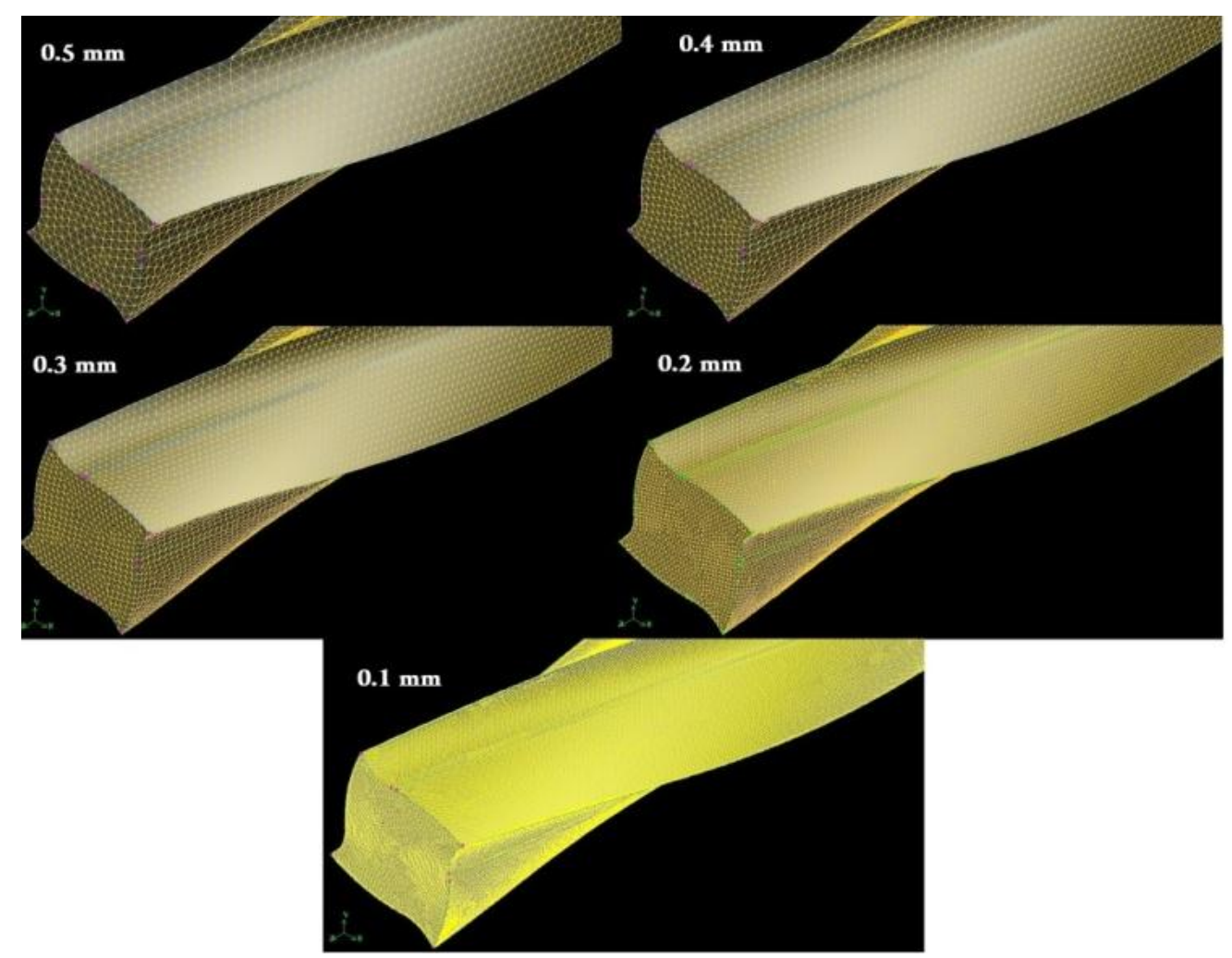

Figure 4: Grid Refinery Process

\section{RESULTS AND DISCUSSIONS}

\subsection{VALIDATIONS}

Firstly, validation was made to confirm the results of smooth tube; this verification will give a confidence for the final numerical results of the corrugated tubes. The validation was present numerically for fluid flow in the smooth tube of stainless steel tube has $2 \mathrm{~mm}$ thickness, nominal diameter Dn of $10 \mathrm{~mm}$ and 2 m length.

Nusselt number for the smooth pipe compared with both Churchil and Ozoe equation [9] beside Shah and London equation [23]. Churchil and Ozoe [9] prescribed an equation that covers the entrance and fully develops region confirmed for $\mathrm{Pr}$ about 0.7 to 10 , and has reliable intimate of small $\mathrm{Gz}$ and large $\mathrm{Pr}$, as:

$$
N u_{x}=\left[4.364\left(1+\left(G_{Z} / 29.6\right)^{2}\right)^{1 / 6}\right] *\left[1+\left[\frac{G_{Z} / 19.04}{\left(1+(\operatorname{Pr} / 0.0207)^{2 / 3}\right)^{1 / 2}\left(1+\left(G_{Z} / 29.6\right)^{2}\right)^{1 / 3}}\right]^{3 / 2}\right]^{1 / 3}
$$

Where:

$$
G_{Z}=\frac{\pi}{4 x_{*}}=\left[\left(\pi \operatorname{Re}_{D_{n}} \cdot \operatorname{Pr}\right) / 4\left(x / D_{n}\right)\right]
$$

Moreover, Shah and London equation [23] was:

$$
N u=\left\{\begin{array}{cl}
1.953(\operatorname{Re} \operatorname{Pr} D / L)^{1 / 3} ; & (\operatorname{Re} \operatorname{Pr} D / L) \geq 33.3 \\
4.364+0.0722 \operatorname{Re} \operatorname{Pr} \frac{D}{L} ; & (\operatorname{Re} \operatorname{Pr} D / L) \leq 33.3
\end{array}\right.
$$




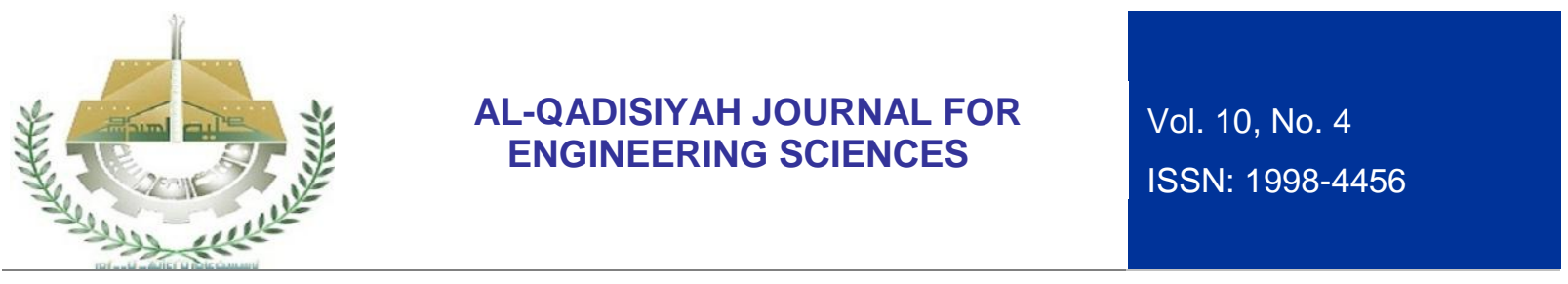

Figure 5 shows a good agreement with the current outcomes with acceptable deviations of $\pm 4.7 \%$ and $3.8 \%$ with the data reported by [9] and [23] respectively. This deviation came from both assumption approximations and numerical error.

On the other hand, the friction factor is habitually used for the validation of pressure drop, where the validation achieved by comparing the numerical results of smooth tube with the Darcy friction factor as in the following Figure 6 and equation (15) with maximum deviations of $\pm 5.87 \%$ occurs at $\operatorname{Re}=1500$.

$f=64 / \mathrm{Re}$

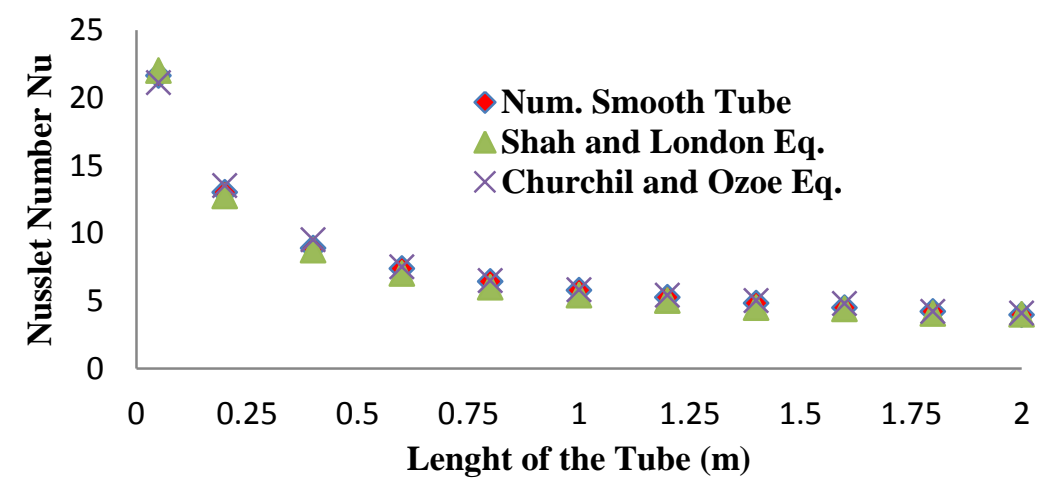

Figure 5: Validation of Nusselt Number for Smooth Tube.

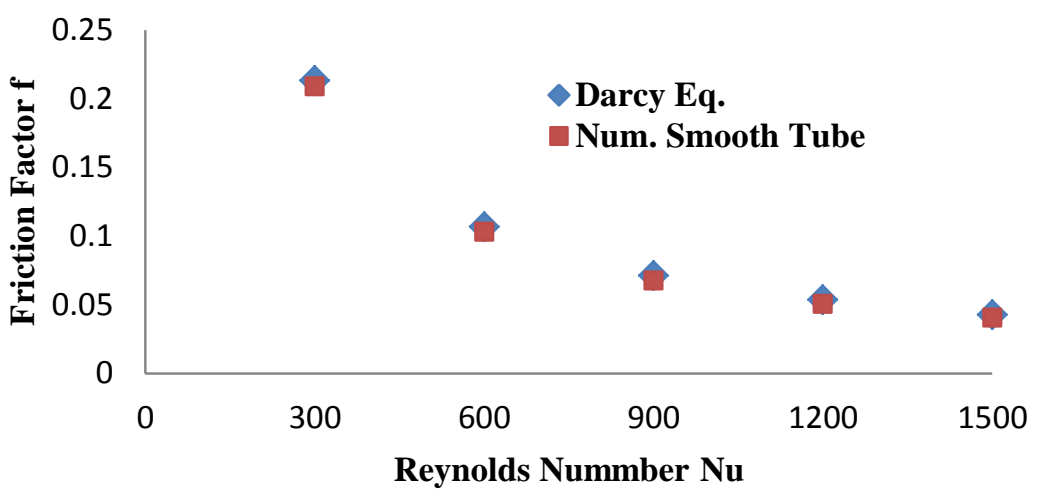

Figure 6: Friction Factor Validation of Smooth Tube

\subsection{HEAT TRANSFER RESULTS}

The reasonable matching of both Nusselt number and friction factor validation for both the current numerical results give an indication and corroboration about the fidelity of the current study. For further reliability of the ANSYS simulation, the calculated Nusselt number of Severity Index $\varphi=1.98 \times 10^{-2}$ is compared with the resultant values of previous correlation equations for all Reynolds number values. Srinivasan and Christensen [24] developed a correlation for wide range of spirally tube factors with $0.1 \leq e / D v i \leq 0.4,0.4 \leq p / D v i \leq 7.3,30 \leq \theta \leq 58$ where $D_{v i}$ is the volume-based tube inner diameter as:

$N u_{D v i}= \begin{cases}0.014 \operatorname{Re}_{\mathrm{Dvi}}^{0.842}\left(\frac{e}{D v i}\right)^{0.067}\left(\frac{p}{D v i}\right)^{0.293}\left(\frac{\theta}{90}\right)^{-0.705} \operatorname{Pr}^{0.4} & \text { For } \operatorname{ReD}_{\mathrm{vi}} \leq 5000 \\ 0.064 \operatorname{Re}_{\mathrm{Dvi}}^{0.773}\left(\frac{e}{D v i}\right)^{-0.242}\left(\frac{p}{D v i}\right)^{-0.108}\left(\frac{\theta}{90}\right)^{0.599} \operatorname{Pr}^{0.4} & \text { For } \operatorname{Re}_{\mathrm{vi}}>5000\end{cases}$

Also Barba et al [25] developed a correlation equation for laminar flow of $100<\mathrm{Re}<800$ for ethylene glycol fluid flow as follows: 


\section{AL-QADISIYAH JOURNAL FOR ENGINEERING SCIENCES}

Vol. 10, No. 4

ISSN: $1998-4456$

$N u=0.7345 \operatorname{Re}^{0.5689} \operatorname{Pr}^{-0.0374}$

Abdel-Kariem and Fletcher [26] suggested a laminar correlation equation for fluid flows through corrugation tubes; valid to the range of Reynolds number at $70 \leq \operatorname{Re} \leq 1200$ at different value of $\theta$, where $\theta$ is the helix corrugation angle as in the expression below:

$N u=0.777 \operatorname{Re}^{0.444}(\theta / 45)^{0.67}$

Figure 7, shows the numerical Nusselt number versus Reynolds number for difference values in the severity index as well as the validation of the Nusselt number with theoretical values. As Reynolds number increases, Nusselt number Nu for both corrugated pipe and smooth tubes increase steadily. Obviously, the Nusselt number supposed to increase as both corrugation height and pitch increases, in other words, the heat transfer enhancement gets an increase as the severity index increase.

As it was expected, the severity index helps to mix the fluid layers next to the tube wall while keeping the core flow intact. This behavior has two merits. First, enhancing the heat transfer by the disturbance near the wall; second; it keeps the flow laminar in the core zone, which minimizes the pressure loss. The mentioned contours figure strongly indicate that the coefficient of the heat transfer gets enhances through the growth of severity index due to the decrease of the overall wall temperature with increase of severity index. This attributes to the turbulence in the secondary flow region that helps to mix the fluid layers and lead to increase the rate of heat transferred from the wall toward the fluid.

The differences of the water properties in this study and the ethylene glycol properties in Barba et al [25] beside their fixed parameters like $e=1.5 \mathrm{~mm}$ and $p=11.5 \mathrm{~mm}$ are the reasons of the dissimilar values of Nusselt number. Moreover the variations in helical corrugation angles were the reasons of the difference between the values of this study compared with Abdel-Kariem and Fletcher [26]. Srinivasan and Christensen [24] obtained the maximum divergence was $\pm 4.91 \%$ so the numerical study for the corrugated tubes in different values of severity index can be acceptable.

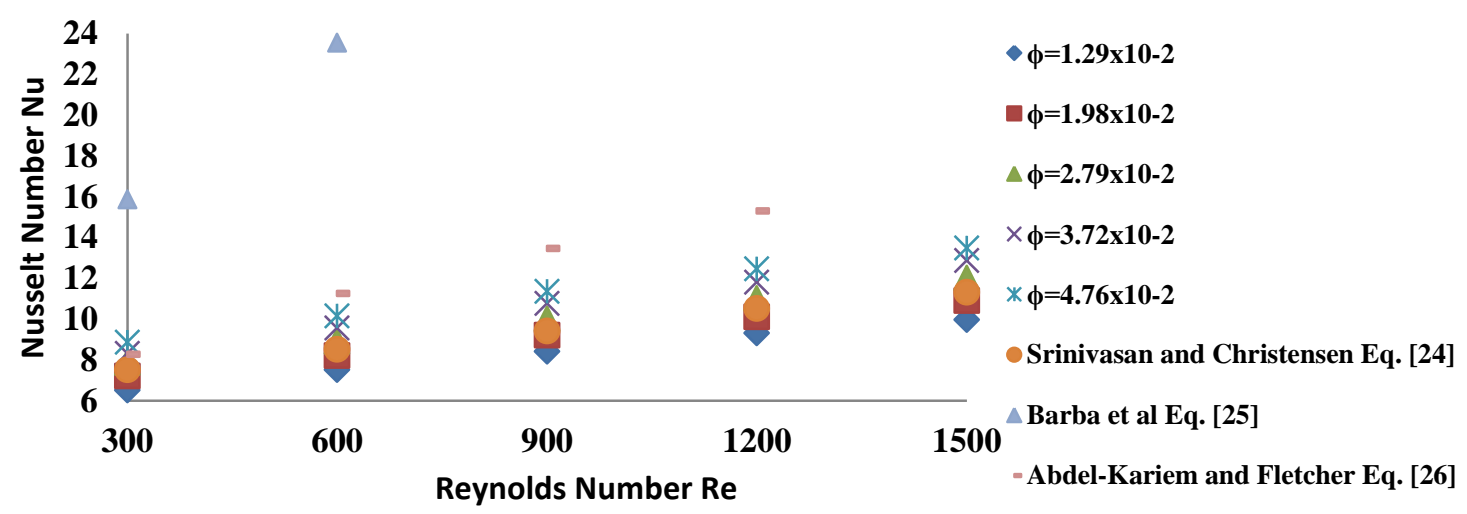

Figure 7: Nusselt Number versus Reynolds Number for Different Severity Index.

Figure 8 shows the temperature distribution through the corrugated tube for $\varphi=1.29 \times 10^{-2}, 2.79 \times 10^{-2}$, $4.76 \times 10^{-2}$ at Reynolds Number of 300 to 1500 for the corrugated tubes. For the same Reynolds number, and once the severity index increases, the mixing of the fluid develops according to eddies generated due to the increase of the twisted wall compared with low severity index. Although of the figures declared that, the highest temperature increases with rising of the severity index, this is because of a miniature amount of fluid compared with the main flow encloses near the corners which has a high local temperature compared with the mean fluid flow temperature through the pipe. As the inlet velocity increases, Reynolds number increases, and mass flow rate will enlarge, therefore the overall heat transfer will enhance too thus the surface temperature of the tube decreases. 


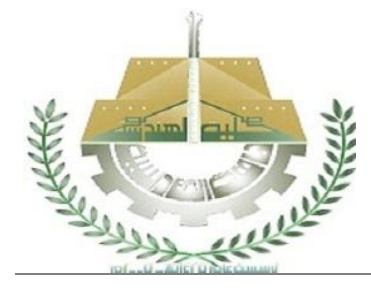

\section{AL-QADISIYAH JOURNAL FOR ENGINEERING SCIENCES}

Vol. 10 , No. 4

ISSN: $1998-4456$

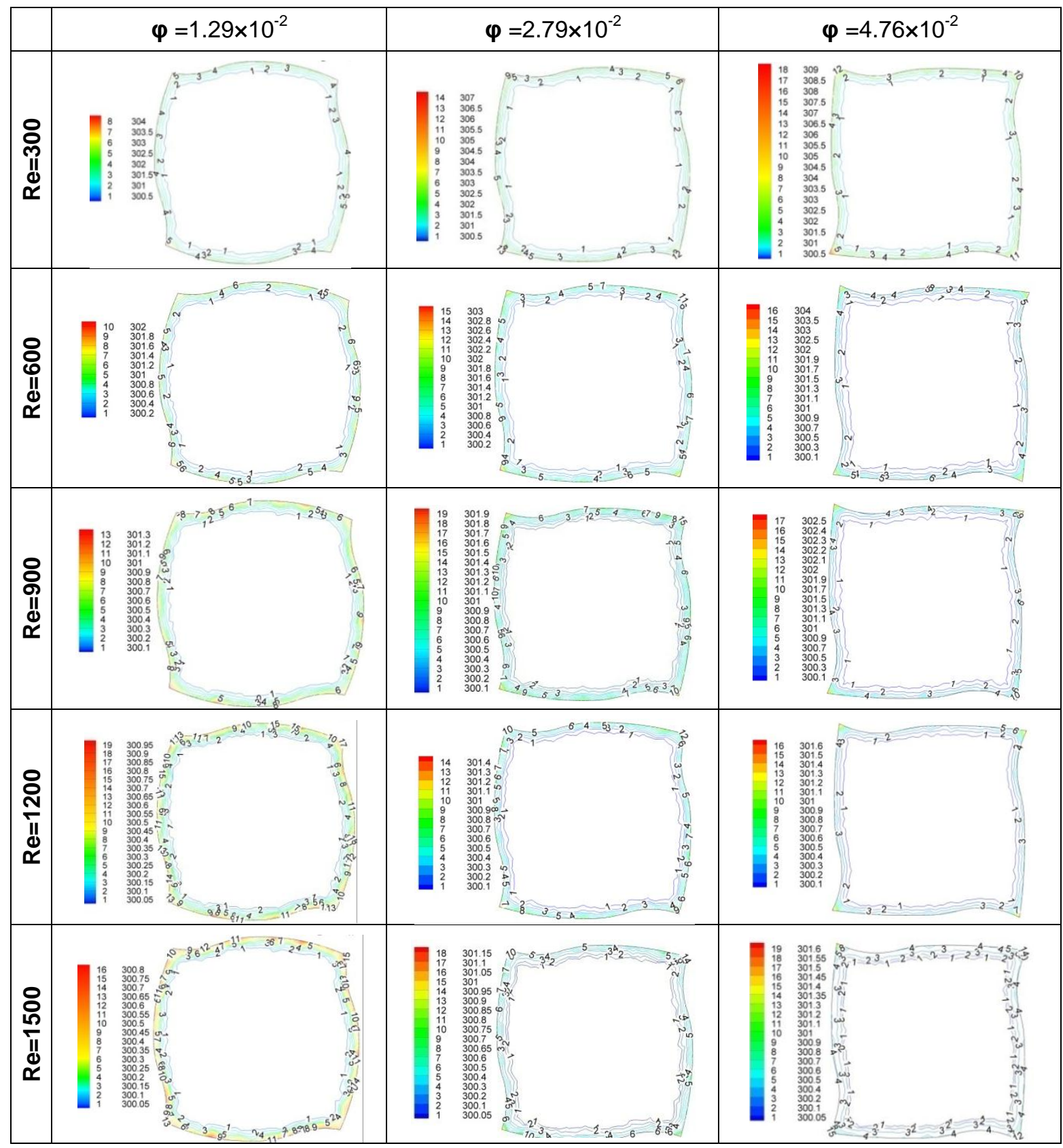

Figure 8: Temperature Contour with Severity Index of $1.29 \times 10^{-2}, 2.79 \times 10^{-2}, 4.76 \times 10^{-2}$

at Reynolds Number of 300 to 1500

\subsection{FRICTION FACTOR RESULTS}

As it commonly known, when the inlet velocity increases, means Reynolds number increase and the mass flow rate increase too so the velocity contour increases as it clear shown in the Figure 9, for the corrugate tubes at $R e=300,900$ and 1500 . As the severity index rises, eddies will generated gradually, the local velocity will decrease, and the local pressure will increase which is satisfied the Bernoulli Equation. While Figure 10 shows the pressure contours of the integer corrugation height at $R e=300,900$ and 1500 . It clearly indicates the actual case of losing energy (pressure loss) as both of corrugation height and $\operatorname{Re}$ increase. Pressure loss reaches the maximum value at the highest value of $\varphi=4.76 \times 10^{-2}$ and $R e=1500$. This figure also shows that the maximum pressure occurring at the corrugation gap region due to the induced turbulence caused by the corrugation and there was an increase in pressure loss of range $20.6-39.1 \%$. 


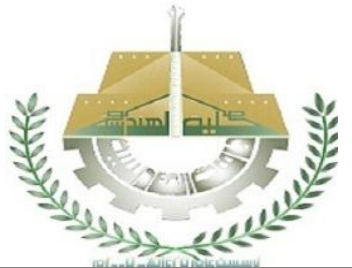

AL-QADISIYAH JOURNAL FOR ENGINEERING SCIENCES

Vol. 10, No. 4

ISSN: $1998-4456$

\begin{tabular}{|c|c|c|c|}
\hline & $\boldsymbol{\varphi}=1.29 \times 10^{-2}$ & $\boldsymbol{\varphi}=2.79 \times 10^{-2}$ & $\boldsymbol{\varphi}=4.76 \times 10^{-2}$ \\
\hline 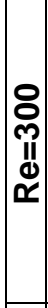 & 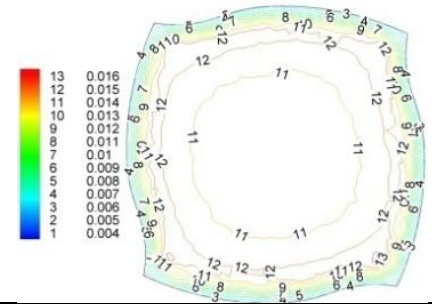 & 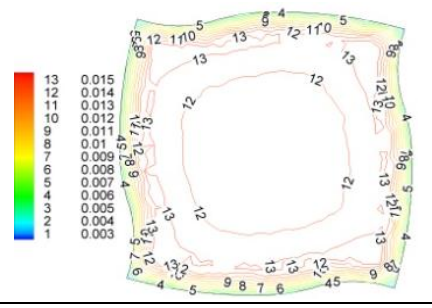 & 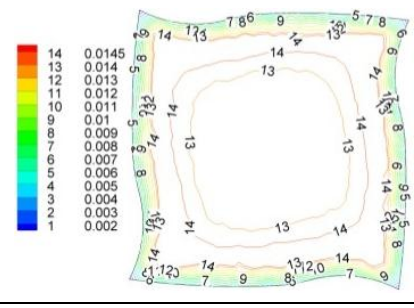 \\
\hline 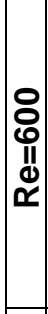 & 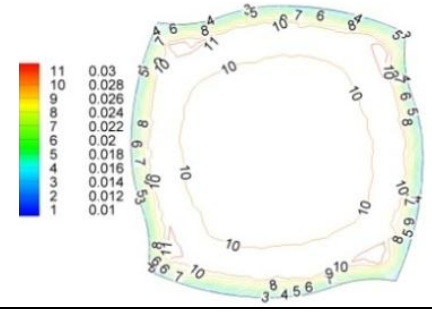 & 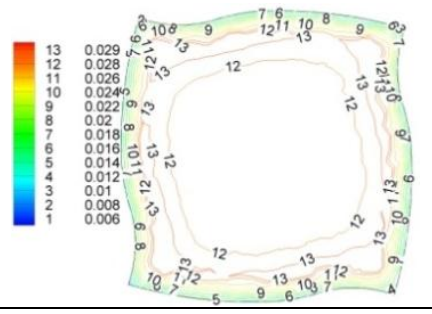 & 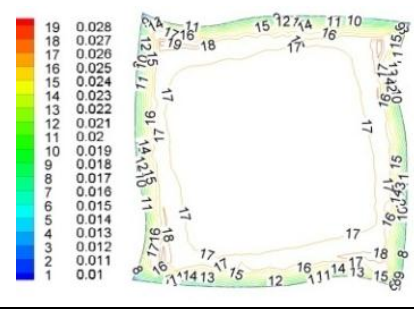 \\
\hline 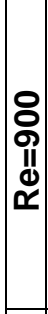 & 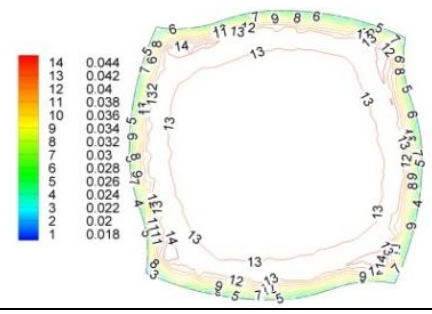 & 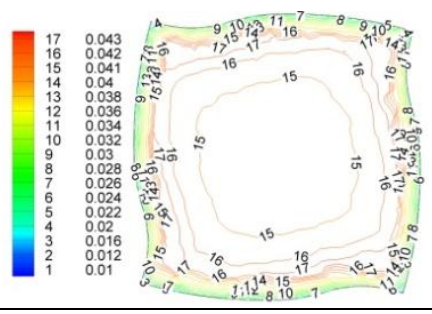 & 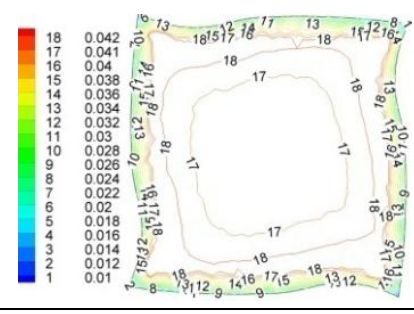 \\
\hline 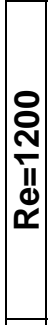 & 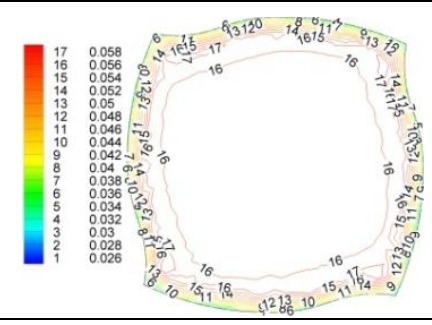 & 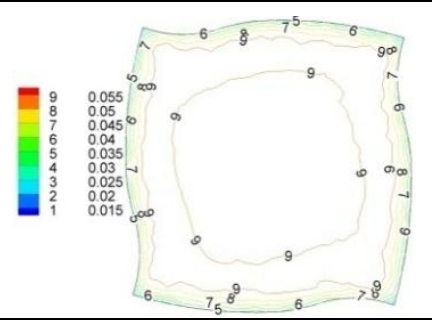 & 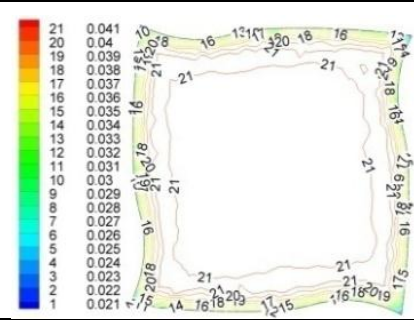 \\
\hline 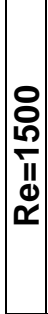 & 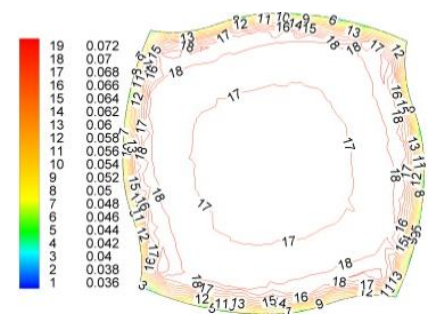 & 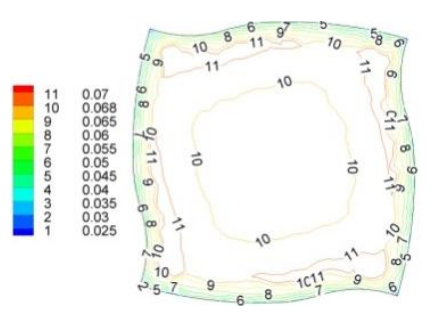 & 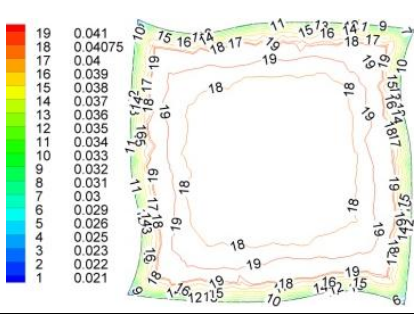 \\
\hline
\end{tabular}

Figure 9: Velocity Contours with Severity Index of $1.29 \times 10^{-2}, 2.79 \times 10^{-2}, 4.76 \times 10^{-2}$ at $\mathrm{Re}=300$ to 1500

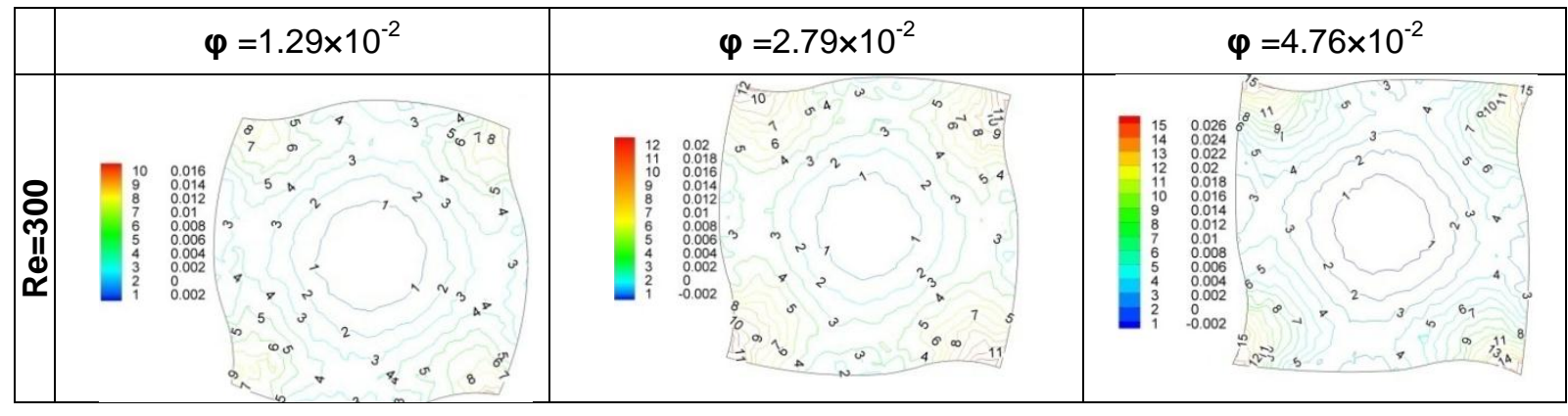



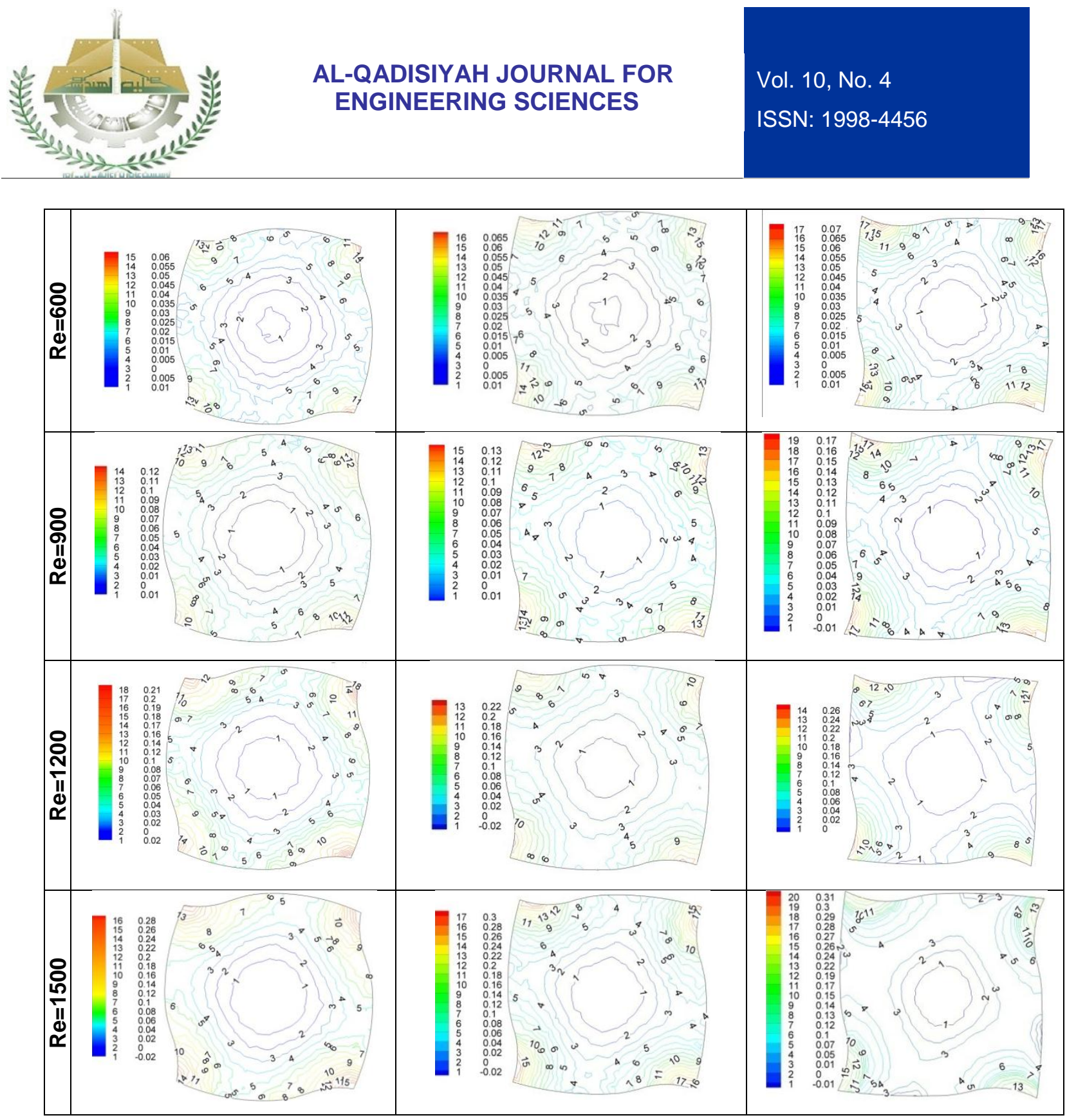

Figure 10: Pressure Contours with Severity Index of $1.29 \times 10^{-2}, 2.79 \times 10^{-2}, 4.76 \times 10^{-2}$

at $\mathrm{Re}=300$ to 1500

As it commonly known, the energy dissipation increases as the flow rate increase. Analogously, the increase in Reynolds number causes an increase in the pressure loss as shown in Figure 11. The desired heat gained is accompanied with appreciable pressure loss and pumping power. The figure shows the of increasing Reynolds number on the friction factor of the numerical study values at the severity index $\boldsymbol{\varphi}=1.98 \times 10^{-2}$ and compared with another previous correlation equations. Srinivasan and Christensen [24] offered a correlation equation as:

$$
f= \begin{cases}\left.0.554(64.0) \operatorname{Re}_{\mathrm{Dvi}}-45.0\right)\left(\frac{e}{D v i}\right)^{0.384} & \text { For Re } \mathrm{D}_{\mathrm{vi}} \leq 1500 \\ *\left(\frac{p}{D v i}\right)^{(-1.454+2.083 e / D v i)}\left(\frac{\theta}{90}\right)^{-2.42} & \\ 1.209 \operatorname{Re}_{\mathrm{Dvi}}^{-0.261}\left(\frac{e}{D v i}\right)^{(1.26-0.05 p / D v i)} & \\ *\left(\frac{p}{D v i}\right)^{(-1.66+2.033 e / D v i)}\left(\frac{\theta}{90}\right)^{(-2.669+3.67 e / D v i)} & \text { For Re } \left.\mathrm{D}_{\mathrm{vi}}\right) 1500\end{cases}
$$




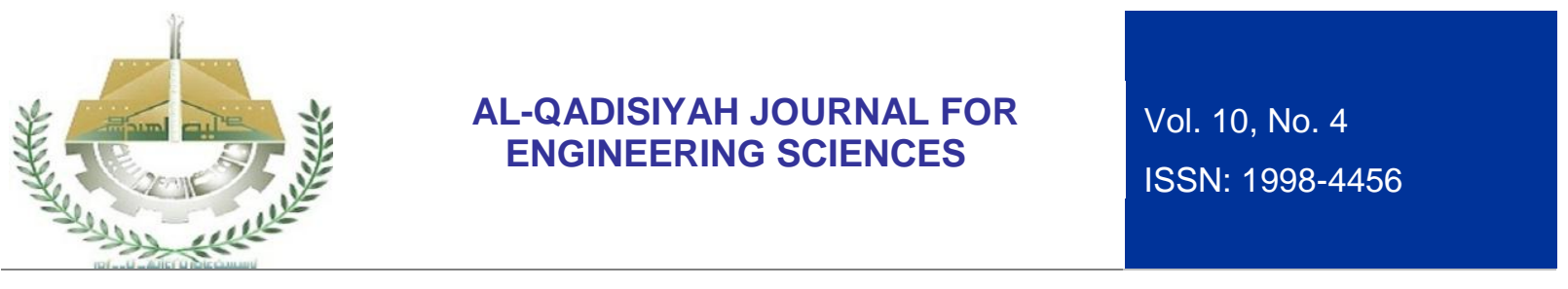

While Barba [25] manifested another correlation equation for ethylene glycol fluid flow tested to $100<$ $\mathrm{Re}<800$ as follows:

$$
f=61.639 \mathrm{Re}^{-0.8602}
$$

Meng et al [27] presented correlation equation for oil flow in circular and elliptical tubes by $p / D=2-3$ for $500 \leq \operatorname{Re} \leq 50000$ as:

$$
t=1.54 \mathrm{Re}^{-0.32}
$$

The deviation of Barba [25] and Meng et al [27] equations were as the different of the thermo physics properties between the water for this study and the other types of the work fluids. Srinivasan and Christensen equation obtained a maximum divergence of $\pm 3.1 \%$ so that it can be conclude that the other values of the Severity Index are acceptable.

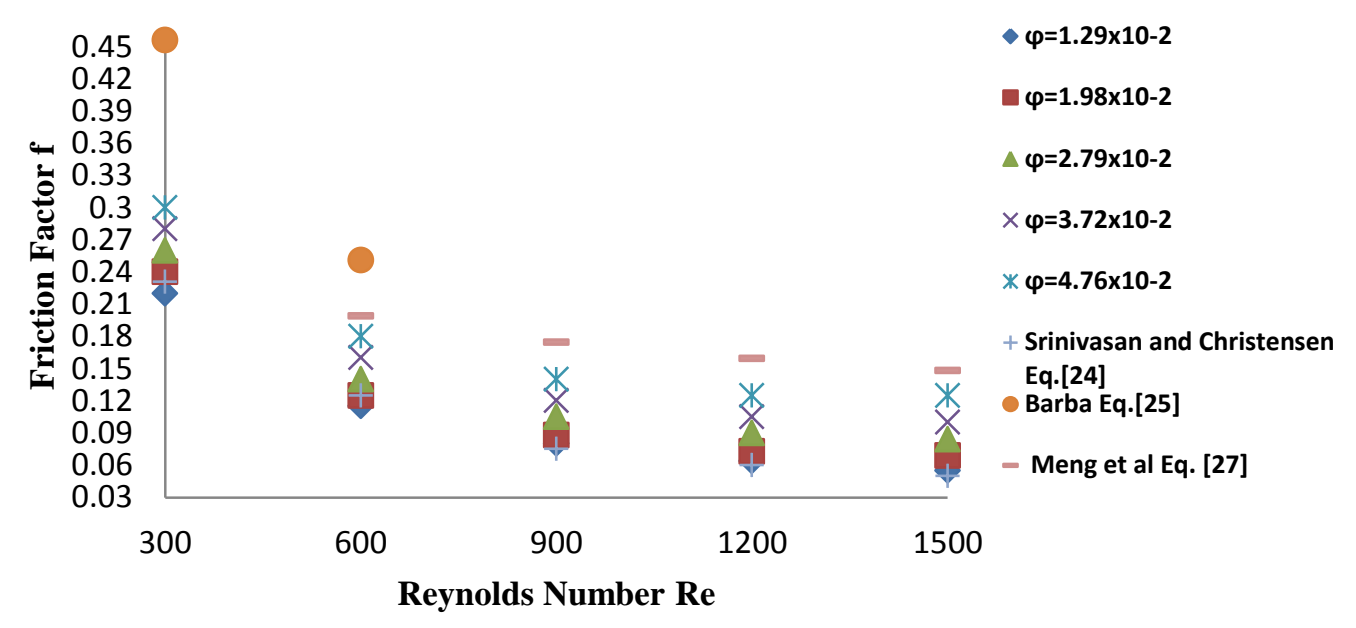

Figure 11: Friction Factor against Reynolds Number for Various Severity Index

\subsection{Thermal Performance Factor}

Figure12 shows Nusselt number ratio $\mathrm{Nu}_{d} / \mathrm{Nu}_{s}$ between the corrugated tubes with the smooth tube against Reynolds number. The Nu ratio indicates that the corrugated pipe is better than the smooth pipe that means that the heat transfer performance of the corrugated pipe is more efficient and the largest value in $\mathrm{Nu} d N u_{s}$ was reach 1.560. In additional the resistance coefficient ratio; $f_{d} f_{s}$ through the corrugated tube increases directly with booth the Reynolds number and Severity Index along with maximum value 1.80-2.93 times the smooth tube for Reynolds number from 300-1500 respectively as shown in Figure 13.

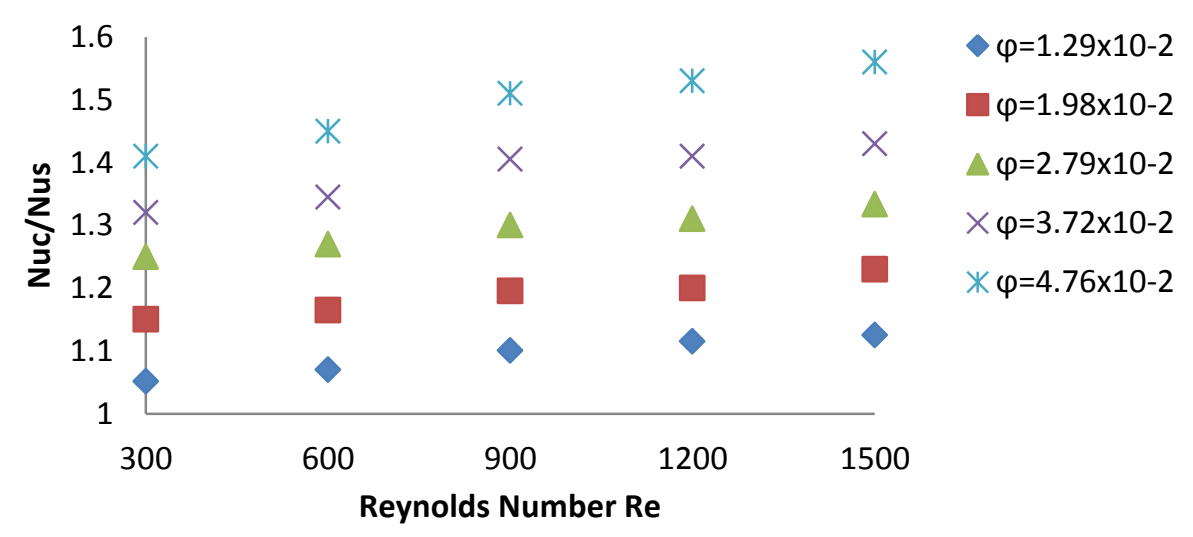

Figure 12: Nusselt Number Ratios with Reynolds Number 


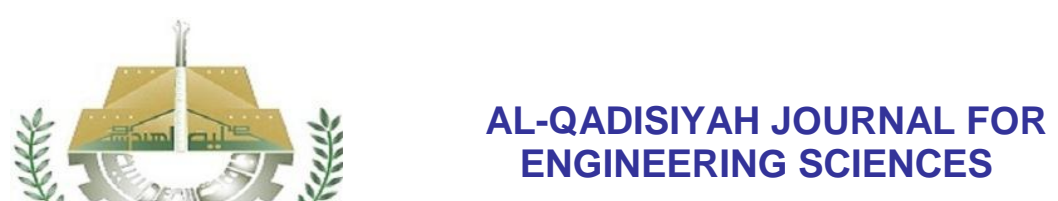

Vol. 10, No. 4

ISSN: $1998-4456$

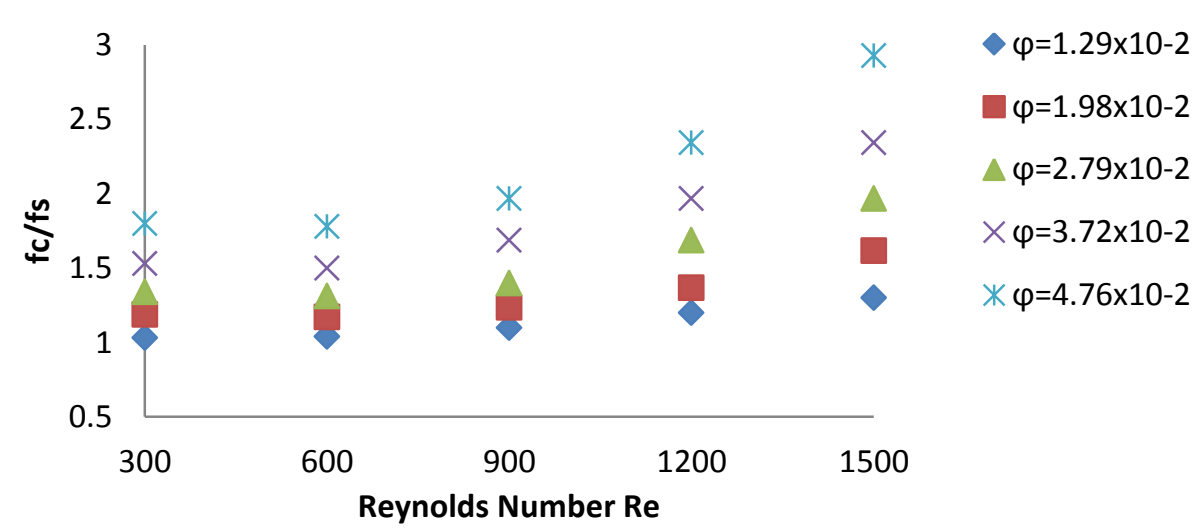

Figure 13: Friction Factor Ratios with Reynolds Number

This factor was proposed to describe the overall performance of an enhanced tube or tube with the promoter. The gained heat transfer ratio to the gained pressure loss simply represents the thermal performance factor as in the following equation [20].

$\eta=\left(N u_{c} / N u_{s}\right) /\left(f_{c} / f_{s}\right)^{1 / 3}=f\left(\operatorname{Re}_{s}\right)$

The thermal performance of the current cases shows in Figure 14. The figure shows the tube of highest severity index is the best one in term of overall thermal performance, while the tube of lowest severity index is the worst one and the maximum enhancement was in the range of Reynolds numbers 900 .

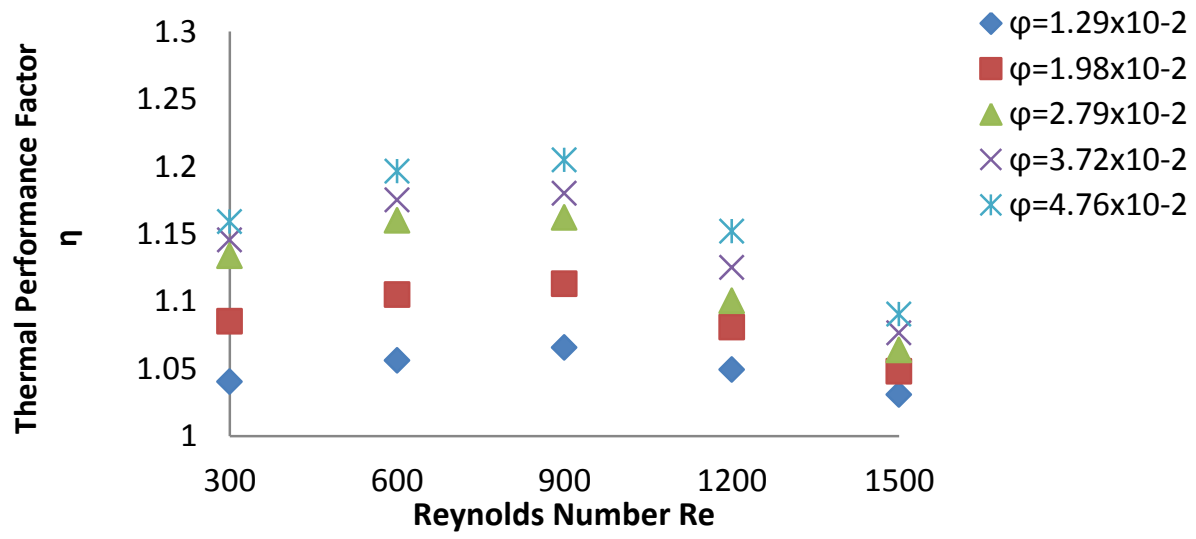

Figure 14: Thermal Performance Factor against Reynolds Number for Various Severity Index

\subsection{ANALYSIS OF DIFFERENT FLUID TYPES}

Air, water and engine oil investigated to explore the effects of the medium properties on the overall characteristics of the heat transfer for smooth and corrugated tube. By varying the medium type, the fluid properties change and the relation between fluid property like $\mathrm{Pr}$ and $\mathrm{Nu}$ could be produced by the numerical method. Physical characteristics of the fluids at temperature $350 \mathrm{~K}$ exposed in Table 2 [28].

Table 2: PHYSICAL PROPERTY OF THE WORKING FLUIDS [28]

\begin{tabular}{|c|c|c|c|c|c|}
\hline Fluid at(350K) & $\boldsymbol{\rho} \mathbf{~ k g} / \mathbf{m}^{\mathbf{3}}$ & $\mathbf{C p ~} \mathbf{~ K J} / \mathbf{K g . K}$ & $\boldsymbol{\mu ~ N . s} / \mathbf{m}^{\mathbf{2}}$ & $\mathbf{K ~ \mathbf { W } / \mathbf { m }} .^{\mathbf{0}} \mathbf{C}$ & $\mathbf{P r}$ \\
\hline Air & 0.995 & 1.005 & 0.00002082 & 0.03003 & 0.7 \\
\hline Water & 973.7 & 4.191 & 0.000372 & 0.668 & 2.33 \\
\hline Engine Oil & 583.9 & 2.118 & 0.0356 & 0.138 & 546 \\
\hline
\end{tabular}


As it concluded in the water cases study, the best corrugation type to enhance the heat transfer depends on the Severity Indexes occurs at $\varphi=4.76 \times 10^{-2}$, so that this severity index will used to get the evaluations for the other fluid mediums. The distribution of augmentation ratio of the heat transfer $N u_{d} N u_{s}$ that evaluated for the three fluids through the smooth and corrugated tube as shown in Figure 15. It can be conclude that the Nusselt number Nu of four start corrugate pipe is better than the smooth pipe and for the greater Prandtl number working fluid like engine oil, Nusselt number will be better than the lower Prandtl number working fluid like in air. so that It can be establishing that the progression of Nusselt number ratio $N u_{d} / N u_{s}$ from low to high as: air, water, engine oil. Largest ratio of Nusselt number $N u_{d} N u_{s}$ could be reach 5.778 , which points to that for the engine oil medium with a high Pr cause a higher value in the augmentation of the heat transfer.

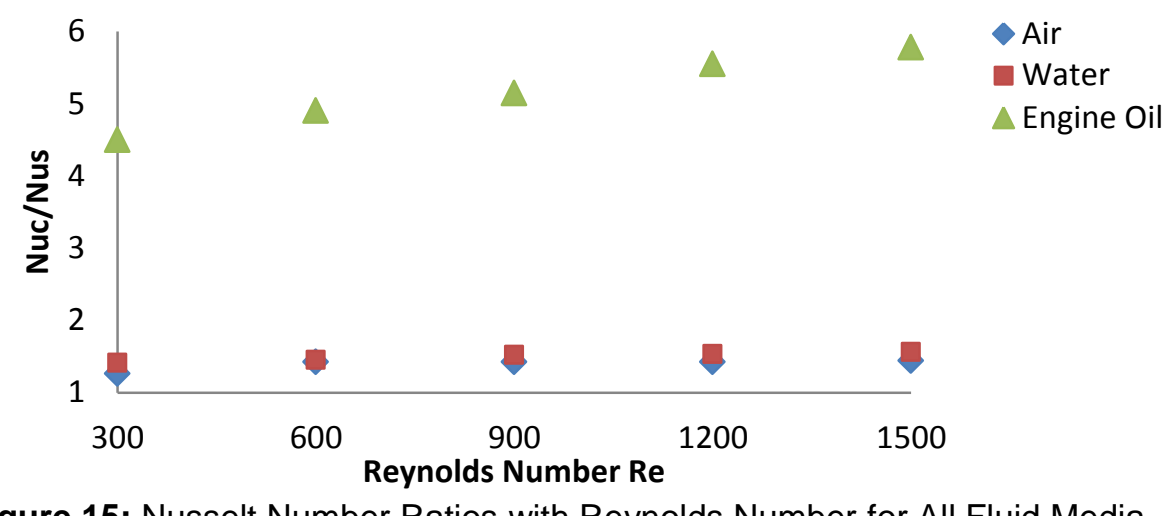

Figure 15: Nusselt Number Ratios with Reynolds Number for All Fluid Media

Figure 16 shows the friction factor ratio for the different working mediums (air, water and engine oil) at Severity Index $\varphi=4.76 \times 10^{-2}$ with all range of Reynolds numbers. It can be shown the curves act as the same behavior of the water and the effect of the fluid properties on the resistance of the fluid inside the pipe is not large so that the curves of the friction factor ratio $f_{d} / f_{s}$ is similar. It's clear that the friction factor for all fluid mediums for the corrugated tube is higher than the smooth tube. The curve of the engine oil medium is higher the others as the high viscosity compared with the other working fluids so the pumping power will be more than the other fluids.

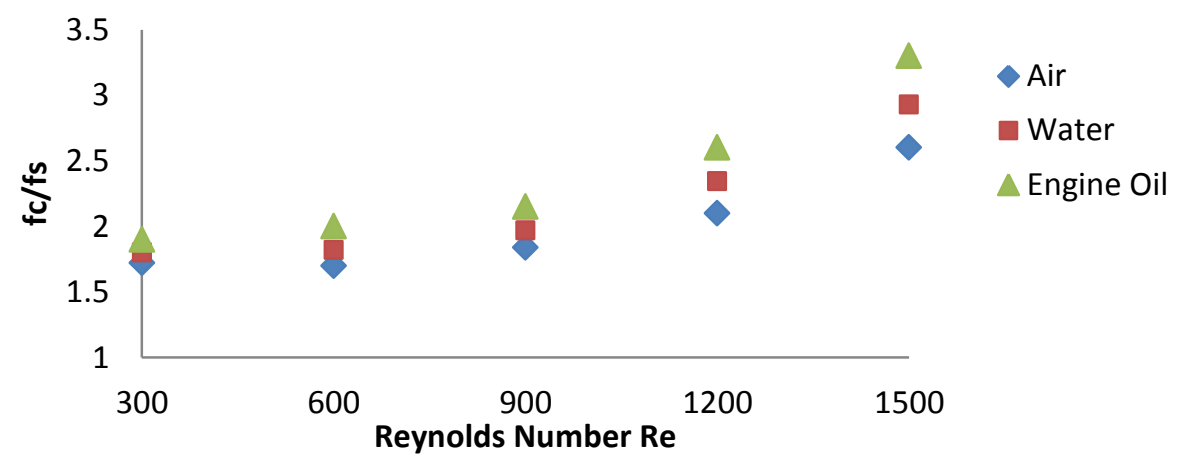

Figure 16: Friction Factor Ratio with Reynolds Number for All Working Fluid

Figure 17 shows the thermal performance factor against the Reynolds number for the corrugated tube with Severity Index $\varphi=4.76 \times 10^{-2}$ for the air, water and engine oil. It can be noted that the engine oil has a higher thermal performance than the other fluids as the high values of the Nusselt number ratio $N u_{d} N u_{s}$ that acts in significant outcome more than the effect of its friction factor ratio $f_{c} / f_{s}$. The maximum values of the Thermal performance ratio was not in the same Reynolds number but its change in the range of $R e=800$ 1200 from the low Prandtl number to the high Prandtl number as the fluid properties are changed. 


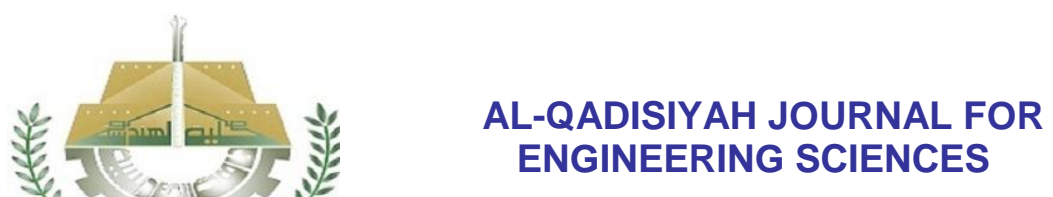

ENGINEERING SCIENCES
Vol. 10 , No. 4

ISSN: $1998-4456$

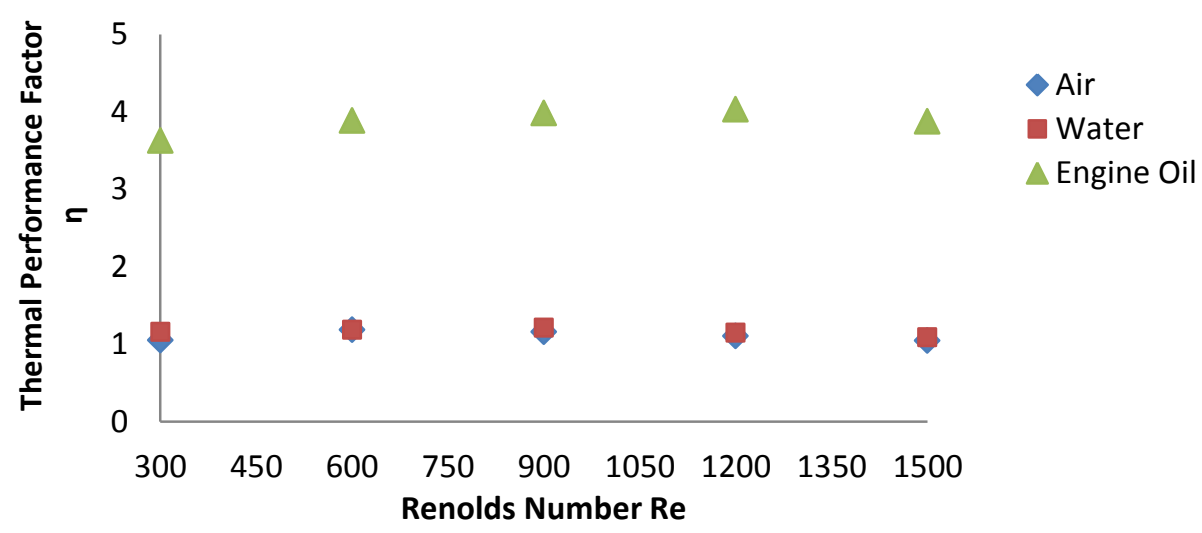

Figure 17: Thermal Performance Factor against the Reynolds Number for All Fluids

As shown before, there are many parameters effects on the heat transfer phenomena as the geometry factors (corrugation depth e and pitch $\mathrm{p}$ ), the properties of the fluid flow and Reynolds number Re, so that the non dimensional factors like e/dn, p/dn, Re and Pr are confirmed by Zhi-Jiang Jin [1] as parameters of the correlation criteria. The general form can expressed as:

$N u=F\left(e / d_{n}, \mathrm{p} / \mathrm{d}_{\mathrm{n}}, \operatorname{Re}, \operatorname{Pr}\right)$

Zhi-Jiang Jin [1] mentions that the correlation equation could be adjust in power function as:

$N u=e^{m 1}\left(e / d_{n}\right)^{m 2}\left(p / d_{n}\right)^{m 3} \operatorname{Re}^{m 4} \operatorname{Pr}^{1 / 3}$

The statistic program SPSS was used to interpret the output results and get the correlation equation using Multiple Regression Analysis. The criteria of the analysis of multiple regression results were; the Multiple R is 0.999949 , R Square is 0.999899 , Adjusted R Square is 0.952265 and the Standard Error is 0.021933. The criterion correlation of the heat transfer through five cases of four-start spirally corrugated pipes is:

$N u=e^{0.38887}\left(e / d_{n}\right)^{0.03644}\left(p / d_{n}\right)^{-0.13939} \operatorname{Re}^{0.26243} \operatorname{Pr}^{1 / 3}$

This criterion correlation is satisfied for water flow inside corrugated tube with $0.1818 \leq e / d_{n} \leq 0.333$, $2.333 \leq p / d_{n} \leq 2.545,300 \leq R e \leq 1500,500 \leq L / e \leq 1000$ and $166.667 \leq L / d_{n} \leq 181.82$. Then a comparison of Nu between simulation and calculation results is shows in Figure 18. The deviation between these results is inside $\pm 3 \%$, so that the correlation for the calculations of heat transfer through the corrugated tube is reliable.

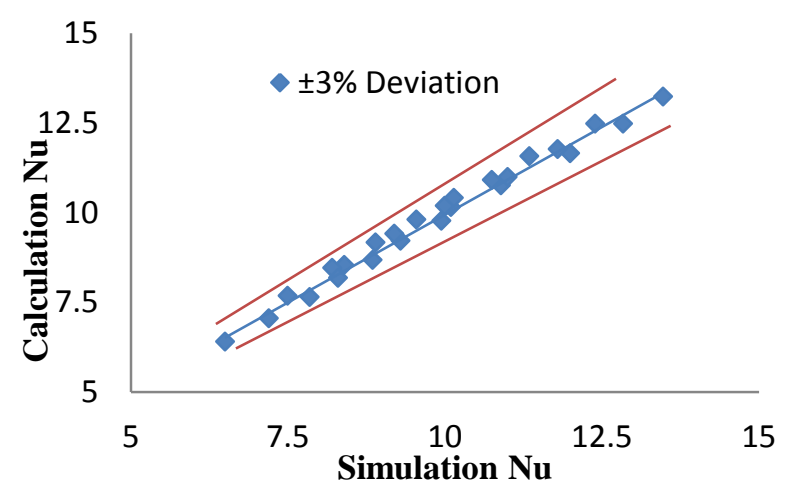

Figure 18: Comparison Nusselt Number Results

\section{CONCLUSION}

Four-start corrugated pipes simulated under constant heat flux condition to clarify the heat transfer enhancement in such passive technique. The outcomes strongly indicated that obtained heat transfer is in 


\section{AL-QADISIYAH JOURNAL FOR ENGINEERING SCIENCES}

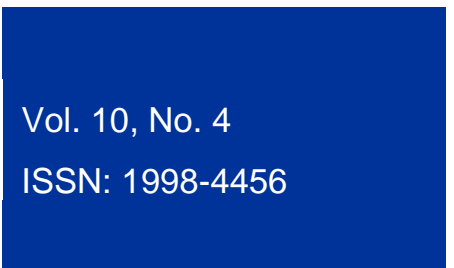

directly proportion with the severity index, also with increase the Reynolds number and the maximum Nusselt number ratio was 1.56 at the highest Reynolds number through $\varphi=4.76 \times 10^{-2}$. Another conclusion is the temperature gradient at the center of pipe is miniature whereas a notice change of the temperature was near the wall that means the main heat transfer procedures near the pipe wall. At constant Reynolds number Re, as the ratio $e / d_{n}$ increase, the Nusselt number Nu increases. It was found that although there are an increase in friction factor of range 1.80-2.93 times the smooth tube values, the enhancement of heat transfer range was about 6.15-33.24\%. As Reynolds number Re increases, the ratios $N u_{c} / N u_{s}$ and $f_{c} / f_{s}$ increases. The most important finding is that the increases in the heat transfer is much more than the increase in pressure loss until a certain threshold $(\mathrm{Re}=900)$ and later, the pressure loss increase and dominate over the heat gained.

It can be concluded a similar behavior for all working fluids, where Nusselt number increase as Reynolds number increases for both the smooth tube and corrugated tube and its values in the corrugated tube are always more the Nusselt number for the smooth tube. Moreover the heat transfer performance of the fluids that has high Prandtl number is best than the lower Prandtl number and the thermal performances was 1.18 times the smooth tube values for air at $\mathrm{Re}=800$ and 4.05 times the smooth tube values for engine oil at $\mathrm{Re}=1200$. Finally, the heat transfer calculation presented as a criterion correlation for corrugated tubes and it validated and proposed to be reliable with $\pm 3 \%$ with the simulation results.

\section{REFERENCES}

1. Jin, Zhi-Jiang; Chen, Fu-Qiang; Gao, Zhi-Xin; Gao ,Xiao-Fei, Effects of Pitch and Corrugation Depth on Heat Transfer Characteristics in Six-Start Spirally Corrugated Tube, Jin-yuan Qian, International Journal of Heat and Mass Transfer, 108, 2017, pg. 1011-1025.

2. Kareem ,Zaid S.; Jaafar, M.N. Mohd; Lazim ,Tholudin M.; Shahrir Abdullah; Abdulwahid ,Ammar F., Passive Heat Transfer Enhancement Review in Corrugation, Experimental Thermal and Fluid Science, 68, 2015, pg. 22-38.

3. Smaisim, G. F.; Fatla, O. M.H.; Medina, A. Valera; Rageb, A.M.; Syred, N., Investigation of Heat Transfer and Fluid Mechanics across a Heated Rotating Circular Cylinder in Crossflow, AIAA Science and Technology Forum and Exposition, San Diego, U.S.A. 4-8 Jan, 2016.

4. Balla ,Hyder H., Enhancement of Heat Transfer in Six-Start Spirally Corrugated Tubes, Case Studies in Thermal Engineering, 9, 2017, pg. 79-89.

5. Liang, Caihang; Tong , Xiaoman; Lei , Tengyue; Li ,Zhenxing; Wu ,Guoshan, Optimal Design of an Air-to-Air Heat Exchangerwith Cross-Corrugated Triangular Ducts by Usinga Particle Swarm Optimization Algorithm, Applied Science 7,2017,pg.554-562.

6. Ardila Marin, J.; Hincapie Zuluaga, D., Casas Monroy, J., Comparison and Validation of Turbulence Models in The Numericalstudy of Heat Exchangers, TECCIENCIA, Vol. 10 No. 19., 2015 ,pg.49-60.

7. Lazim ,Tholudin Mat; Kareem, Zaid S.; Jaafar,M. N. Mohd; Shahrir Abdullah; Abdulwahid, Ammar F., Heat Transfer Enhancement in Spirally Corrugated Tube, International Review on Modelling and Simulations (I.RE.MO.S.), 7, (6), 2014, pg. 123-132.

8. Webb,Ralph L. and Kim, Nae-Hyun,'Principles of Enhanced Heat Transfer', 2Nd Edition, Taylor \& Francis Routledge, 2006.

9. Churchill, S. W., and Ozoe, H., 'Correlations for Forced Convection with Uniform Heating in Flow Over a Plate and in Developing and Fully Developed Flow in a Tube', J. Heat Transfer, 95, 78-84, 1973.

10. Kareem, Zaid S.; Shahrir Abdullah; Lazim, Tholudin M.; Jaafar, M. N. Mohd; AbduIWahid, Ammar F., Heat Transfer Enhancement in Three-Start Spirally Corrugated Tube: Experimental and Numerical Study, Chemical Engineering Science,134,2015, pg.746-757.

11. Saha, S. K., Thermohydraulics of Laminar Flow of Viscous Oil Through a Circular Tube Having Axial Corrugations and Fitted With Centre-Cleared Twisted-Tape, Exp.Thermal Fluid Sci.,38,2012,pg.201-209.

12. Saha, S. K., Thermohydraulics of Laminar Flow Through a Circular Tube Having Integral Helical Corrugations and Fitted with Helical Screw-Tape Insert, Chem. Eng. Commun. 200, 2013, pg.418-436.

13. Kareem, Zaid S.; Jaafar, M.N. Mohd; Lazim, Tholudin M.; Shahrir Abdullah; AbdulWahid, Ammar F., Heat Transfer Enhancement in Two-Start Spirally Corrugated Tube, Alexandria Engineering Journal 54,2015, pg. 415-422. 


\section{AL-QADISIYAH JOURNAL FOR ENGINEERING SCIENCES}

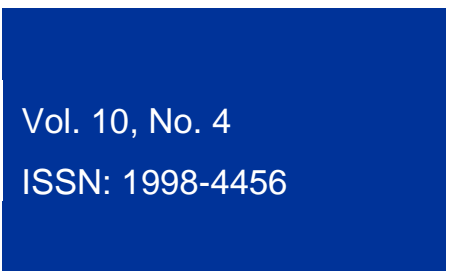

14. Chen X.D.; Xu,X.Y.; Nguang,S.K., Characterization of The Effect of Corrugation Angles on Hydrodynamic and Heat Transfer Performance of Four-Start Spiral Tubes, J. Heat Transfer,123,(6),2001, pg.1149-1158.

15. Zimparov, V., Enhancement of Heat Transfer by a Combination of Three-Start Spirally Corrugated Tubes With a Twisted Tape, Int. J. Heat Mass Transf.,44, (3),2001, pg. 551-574.

16. Ahn,S.W., Experimental Studies on Heat Transfer in The Annuli With Corrugated Inner Tubes, KSME Int. J. 17, (8),2003, pg.1226-1233.

17. Liu ,L.; Ling, X.; Peng,H. Analysis on Flow and Heat Transfer Characteristics of EGR Helical Baffled Cooler With Spiral Corrugated Tubes, Exp. Thermal Fluid Sci.,44, 2013, pg. 275-284.

18. Liu, J.J.; Liu, Z.C.; Liu, W., 3D Numerical Study on Shell Side Heat Transfer and Flow Characteristics of Rod-Baffle Heat Exchangers With Spirally Corrugated Tubes, Int. J. Therm. Sci., 89, 2015, pg.34-42.

19. Promthaisong ,P.; Jedsadaratanachai ,W.; Eiamsa-ard, S., 3D Numerical Study on The Flow Topology and Heat Transfer Characteristics of Turbulent Forced Convection in Spirally Corrugated Tube, Numer. Heat Trans. Part A: Appl. Int. J. Comput. Methodol. 69, (6), 2016, pg. 607-629.

20. Han, H., Li ,B., Wu, H.; Shao ,W., Multi-Objective Shape Optimization of Double Pipe Heat Exchanger With Inner Corrugated Tube Using RSM Method, Int. J. Therm.Sci. 90, 2015, pg. 173-186.

21. Versteeg,H.K. ; Malalasekera, W., An Introduction to Computational Fluid Dynamics the Finite Volume Method, Pearson Education Lmited, 2nd Edition, 2007.

22. ANSYS FLUENT User's Guide. Release 14.0. ANSYS, Inc. November 2011.

23. Shah, R.K.; London, A.L., Laminar Flow Forced Convection in Ducts, 1st Ed., Academic Press, Massachusetts, New York, 1978.

24. Srinivasan, V. and Christensen, R.N., Experimental Investigation of Heat Transfer and Pressure Drop Characteristics of Flow Through Spirally Fluted Tubes, Exp. Thermal Fluid Sci., 5, 1992, pg. 820-827.

25. Barba,A.; Rainieri, S.; Spiga,M., Heat Transfer Enhancement in Corrugated Tube, Int. Commun. Heat Mass Trans., 29, 2002, pg. 313-322.

26. Abdel-Kariem A.H.; Fletcher L.S., A Comparative Analysis of Heat Transfer and Pressure Drop in Plate Heat Exchangers, Proceedings of the Fifth ASME/JSME Thermal Engineering Conference, USA, 1999.

27. Meng,J.; Liang X.; Chen ,Z.; Li, Z., Experimental Study on Convective Heat Transfer in Alternating Elliptical Axis Tubes, Exp. Therm. Fluid Sci.,29, 2005, pg. 457-465.

28. Theodore L. Bergman;Adrienne S. Lavine; Frank P. Incropera; David P. Dewitt, Fundamentals of Heat and MassTransfer. 7th Ed, JOHN WILEY \& SONS,2011.

\begin{tabular}{|l|l|l|l|l|l|}
\hline \multicolumn{4}{|l|}{ Symbols } & \multicolumn{2}{l|}{ Subscripts } \\
\hline e & Corrugation Height & r & Radial Direction & b & Bore \\
\hline f & Friction Factor & Re & Reynolds Number & B & Bulk \\
\hline GCl & Grid Independence Index & T & Temperature & c & Corrugated \\
\hline h & Coefficient of Heat Transfer & u & Fluid Velocity & e & Envelope \\
\hline k & Thermal Conductivity & z & Axial Direction & n & Nominal \\
\hline L & Length of Tube & \multicolumn{2}{|l|}{ Greek Symbols } & s & Smooth \\
\hline Nu & Nusselt Number & $\varphi$ & Severity Index & z & Local \\
\hline P & Pressure & $\rho$ & Density of Fluid & & \\
\hline p & Corrugation Pitch & v & Kinematic Viscosity of Fluid & & \\
\hline Pr & Prandtl Number & $\mu$ & Dynamic Viscosity & & \\
\hline q" & Heat Flux & $\theta$ & Angular Direction & & \\
\hline
\end{tabular}

